\title{
Millennials' Communication Style and Politeness Through Their Memes Using Multimodality Analytical Lens
}

\author{
Diah Kristina $^{1, *}$, Taufik Al Makmun ${ }^{2}$, Sri Kusumo Habsari ${ }^{3}$ and Muhammad \\ Thoyibi $^{4}$
}

${ }^{1,2}$ University Centre of Excellence Javanology for Javanese Traditions, Universitas Sebelas Maret, Surakarta, Indonesia

${ }^{3}$ Department of English, Universitas Sebelas Maret, Surakarta, Indonesia

${ }^{4}$ Faculty of Teacher Training and Education, Universitas Muhammadiyah, Surakarta, Indonesia

*Corresponding author. Email: diahkristina@staff.uns.ac.id,

\begin{abstract}
Memes have been an important growing means of communication among millennials. They were used widely due to its 'fluid' nature and expressiveness. This study is a combined analysis of content and receptive aspects of memes. Employing 50 memes collected from twitter and 25 University students as respondents using multimodality analytical lens, this study found that the memes produced by millennials have their own standard of politeness and require intertextuality skills and perceptions to recognize the meaning and intention of the makers. The mimetic culture has coined a new culture of sharing and showing off with the purpose of criticizing, satirizing, expressing humour, and suggesting from a unique personal angle, using widely recognized images taken from cartoon films, photos, and stories.
\end{abstract}

Keywords: Meme, Memetic Culture, Millennials, Multimodality

\section{INTRODUCTION}

The industrial revolution 4.0 marks the migration from more written oriented into paperless lifestyle using digitalized platforms and media for connectivity, business, entertainment, science, and other social and political purposes. Like a knife with two sides of blade, the digital and media pilgrimage from the conventional into information technologically-based may produce both positive and negative impacts to human lives.

Lisa Nakamura [5] uses Adorno's criticism on media as "a commodity, a product tailored for the masses" to contrast with the optimism in terms of media function proposed by Marshall McLuhan and Benedict Anderson. Both highlight how media have an innate notion aside from its being a source of information and a form of entertainment. Media formulate an "intimate democratic community" - a global village [12] and create the nation into being due to its content of sharing a common identity and conveying ideology [1]. Media, which Althusser in [18] categorizes as one of the ideological state apparatuses function to distribute ideologies as a means of marketing commodities in which social injustice could possibly occur in the way of the emergence of the gap of representation for certain groups, communities, and identities like race and gender as power matters in media production and consumption.

The emergence of digital participatory media, however, has given opportunities for the users to exploit more about their representation. It is a common cultural expression today in which the millennial identity can be expressed through their unique identity of expression in such memes. Thus, social media creates a distinctive virtual culture, including the mode of expression used, e.g. types of language, multimodal 
expression to include visualization, etc. Multimodality refers to the combination use of different semiotic resources or modes in texts and communicative events, such as still and moving image, speech, writing, layout, gesture, and proxemics [11] [19].

The rise of social media as a communication device contributes to the emergence of many distinctive modes of language written expression. The language used in social media tends to be unique which is enabled through and facilitated by the features of social media technology. Anik [2] points out that "the use of emojis in social media" is a kind of "indicative language". Furthermore, in the research focusing on the use of emoji in social media namely whatsapp. Arafah [3] underlines that such emoji's expression is a language that has its grammar distinction as in language in terms of syntax, pragmatic, and semantic. Emoji is a common expression used by social media users especially millennials today. Its characteristics for being short, visual, and meaningful seem to be more practical, yet it functions as an expressive mode of communication.

However, as a personal-operated account, social media expression tends to be based on personal freedom of perpetuating. It is different from those mainstream media channels which have editorial boards as the gatekeeper. Criticisms are often addressed to the use of social media as the source of information as there are questions on the inaccuracy, inadequacy, and even harmfulness in terms of affecting the readers. The expression used may campaign certain beliefs or ideologies as mentioned above. The language used may be copied and reused by the readers. Media contents play a role as a source of information -an inspiration- despite its inaccurate and inadequate information. The migration from face to face interaction into online interaction has shifted the concept of 'face' namely the way people consider others' feelings and dignity, into self-presentation. The cycle of media production and consumption moves beyond its function as a communication tool. Its methods and subjects may shape and reshape society. Language politeness is an example within.

"Linguistic politeness can be defined as the ways in which language is employed in conversation to show consideration for the feelings and desires of one's interlocutors, to create and uphold interpersonal relationships (so-called politic behaviour), and to comply with the rules for what society or one's culture considers appropriate behaviour" (Olmen, 2017). Considering that social media as a self-perpetuating expression, the interpersonal relationship may be neglected as in a standardized behaviour of respecting others like in face-to-face communication. Politeness as political behaviour is corrupted by being individualized on the standard of the speaker.

"Politeness is a pervasive and universal feature of human language use, and research has demonstrated how it motivates the manner in which people phrase their utterances in different settings." [10]. Politeness becomes strategic when there is relatively different power exist between speakers and listeners [16]. Politeness theory as argued by Brown and Levinson [4] is developed from face to face interaction which focuses on face as a subject scrutinized in the course of social interaction. The desire for autonomy and connection with others are the basic wish in social interaction which stimulates individuals to consider face as an important matter. In the digital era, the interaction between individuals is often mediated by certain platform, such as social media platforms. With transformation from face to face into online interaction, the concept of face has been revised by Burk and Kraut [6] into self-presentation. Metts and Grohskopf [13] define self-presentation as "the process by which individuals more or less intentionally, construct a public self that is likely to elicit certain types of attributions from others, attributions that would facilitate the achievements of some goal, usually to acquire social rewards or advantages, or to prevent loss of self-esteem when future failure seems probable" (2003, p.360). Online interaction and behaviour, despite being considered as deliberation, are still expected to engage with certain manners, such as being polite. Subsequently, the idea of face and politeness has been shifted into selfpresentation in which in online interaction it includes the perception of face threats and supports.

There are social expectations in social interaction. Situational contexts and individuals' position influence social expectation in making social interaction. Identity and status, such as socioeconomic, gender, educational, and cultural differences are also important components and can influence the result of activities since they produce perceptions in the mind of both the speakers and the listeners. When the interaction becomes online, these components are brought about by the designers of the platforms. Self-presentation mediates individuals' desire for higher status through constructing online identity. In exchange, interactivity, expression of respect, and sharing similar orientation to something good in common reflect the values in online affairs [15].

This research, then, intends to explore the language and visual expressions found in the social media as in memetic culture to see the representation of the degree of the language politeness representation done verbally and visually. Meme refers to "an 
amusing or interesting item (such as a captioned picture or video) or genre of items distributed widely online especially through social media" (Meriam Webster, nd ed). The current study provides a new perspective on the study especially on the aspects of multimodality, intertextuality, and politeness by employing content and receptive analysis which differs from that of [9], [8], and [7].

\section{MATERIALS AND METHODS}

This study belongs to content analysis employing 50 online memes of millennials taken from twitter with a reader-response survey to explore experience of the millennials as users of the social media. Samples of the memes were then classified in terms of their form, function, and context of use. In order to look closely at the pattern of using the memes and the interconnection among the components, a componential analysis was used.

Respondents of the study were 25 students of the English Department of Sebelas Maret University in Surakarta, Indonesia. Those participating in the survey were the age groups of 20 years $(18,2 \%), 21$ years $(53,6 \%), 22$ years $(24.0 \%)$, and 23 years $(4,2 \%)$ old. There were 3 questions raised in the survey using google form, namely (1) utility of using meme, (2) function of meme, and (3) most impressive memes ever seen.

\section{RESULTS AND DISCUSSION}

Results and discussion in this section is presented under two sub topics: multimodal form and function of memes and perception of the respondents.

\subsection{The Multimodal Form and Function of Memes}

Using componential analysis (Table 3.1), findings of the study show that there are 5 types of memes namely sarcasm, satire, teaser, joke, and threat. Among the five classifications of form, sarcasm has the biggest number (24) that meant to express sarcastic feelings (16), to criticize (3), and to intimidate (2). The sarcasm form of expression varies from sarcasm on stupidity, talkativeness, embarrassing action, being hypocritical, bad-luck, powerlessness, and human evil action. Besides, there are also sarcasms employed to criticize and to intimidate. The latter consist of two memes using the late President Soeharto's smiling face and the picture of him using 'Thanos' infinity stones, a character from the Avenger movie. The contextual clue of 32 years of repressive presidency motivate the twitter users to suggest mutual experiences among them. They therefore, want to represent the intimidating action and repressive experience using the smiling face of the late general.
The (intimidating) ideology by using photos of the late President Soeharto supports Anderson's in [5] and ŽIŽEK [18] claims that media is a means to share content of a common identity and to convey ideology. Below are the types of meme and their conveyed ideologies (Table 1).

The second type of meme is satire (23). There are diverse issues to be satirized like nationalism, intolerance, pathetic attention seeker, recklessness, stupid action, loosing dignity, overthinking, bad behavior during online class, changing behaviour from being religious into empirical, ethnicity, and pun. 13 of the satirizing memes were presented using ideological images of a man kissing a girl which is normally related with compassion but here is used to express hatred.

Table 1. Meme Componential Analysis

\begin{tabular}{|l|c|c|c|c|c|}
\hline \multirow{2}{*}{ Types of Meme } & \multicolumn{5}{|c|}{ Ideologies } \\
\cline { 2 - 6 } & SCI & Cl & II & STI & SEI \\
\hline Sarcasm & 19 & 3 & 2 & & \\
\hline Satire & 5 & 2 & & 10 & 6 \\
\hline Teasing & & & & & 1 \\
\hline Joking & 1 & & & & \\
\hline Threat & & & & & 1 \\
\hline
\end{tabular}

Notes: SCI: Sarcasm Ideology; CI: Criticizing Ideology; II: Intimidating Ideology, STI: Satirizing Ideology, SEI: SelfExpression Ideology

Additionally, many cartoon film characters like Barbie doll using a magnifying glass is created to highlight criticism on stupidity. A strong criticism on online learning is done by using images of young boys covering themselves in blankets while having the class. It represents honestly the existing condition during the pandemic, a portrait of how hopeless the teaching and learning among particular learning groups has been. An image of a black man dragging a female to run for the exit corridor may have implication on racism with a label of 'bad decision' put on the body of the black man. It reminds us of how wrong decision may be taken in a situation of emergency, but then the question is, why using an image of a black man with a noticeable label put on his chest? There are two satirical memes criticizing Indonesian's intolerance and the Javanese who used to be collies on asphalt-road construction of AnyerPanarukan during the Dutch's occupation. Now the road is changed into concrete-based. Contextually, this meme may be made with an intention to tease the Javanese who used to be working as road construction 
workers; everything remains the same only materials of the road that change.

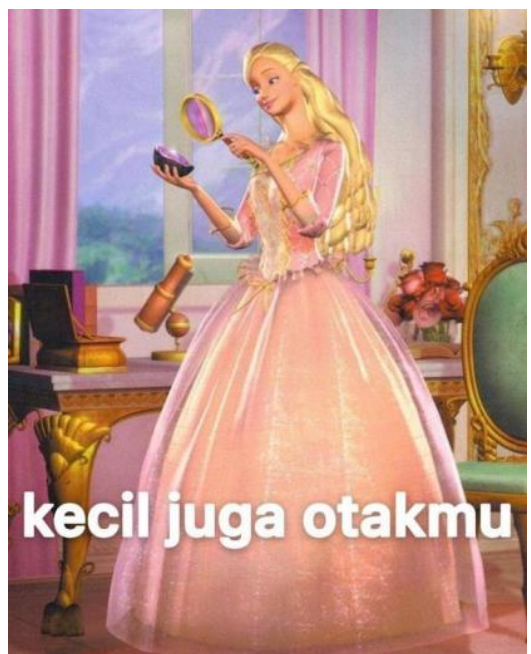

Figure 1. Barbie doll using a magnifying glass

\section{me attending my classes}
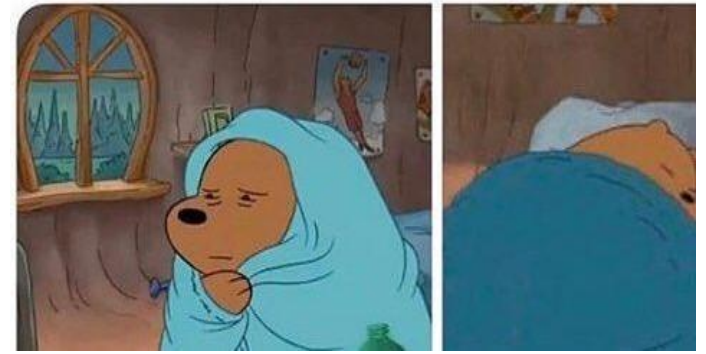

Figure 2. Young boys covered with blankets

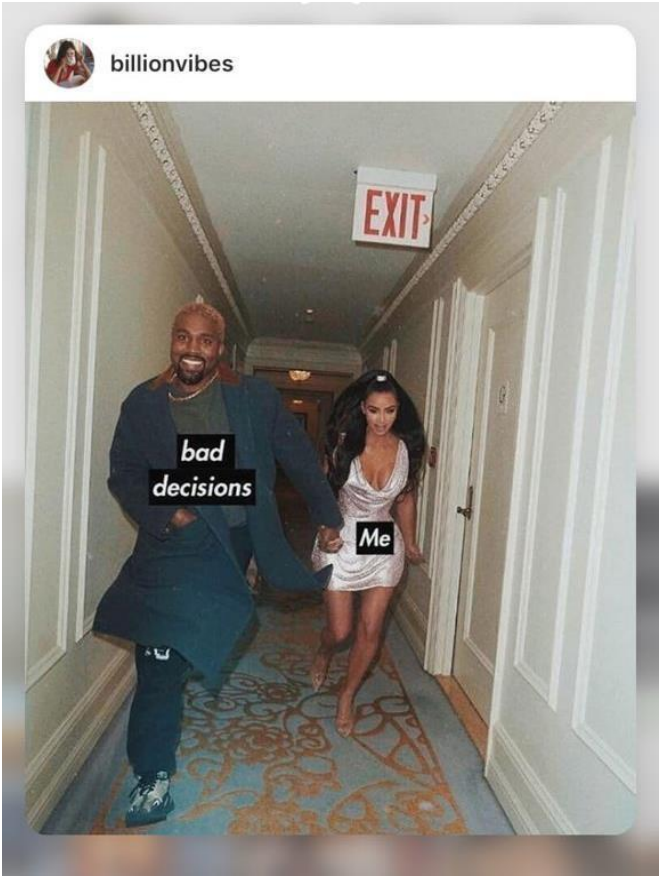

Figure 3. A black man dragging a female

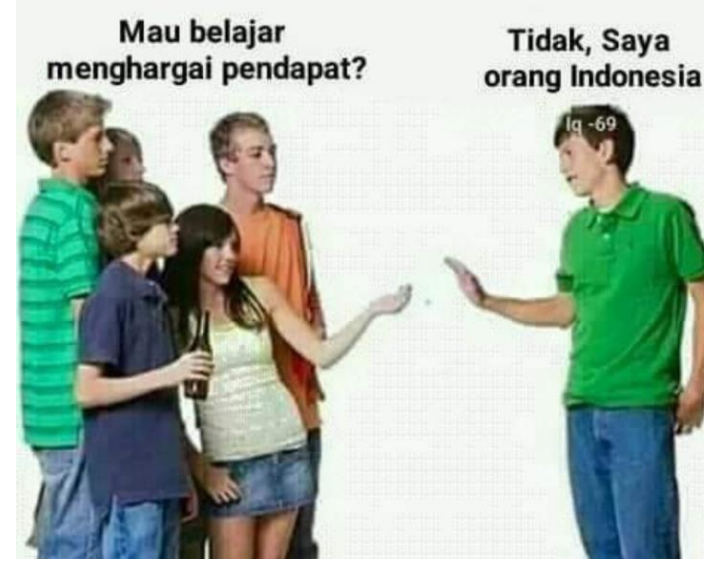

Figure 4 Indonesian's intolerance

The meme culture found in the study indicates a strong notion of freedom perpetuated in the unique ways of expressing ideas using characters in cartoon films, popular figures, and other widely-recognized images to build mutual perception between the meme creators and their audience. Thus, a notion of intertextuality lays a strong ground for a mutual comprehension on the meaning and intention of the memes shared.

According to Anik [2], the language used in social media tends to be unique. This is primarily enabled through and facilitated by the features of social media technology. One of the uniqueness we believe has to do with the notion of politeness which has its own standard and adequacy, especially when it 
relates to the self-representation of the meme maker. In another word, there has been an intimate democratic community coined by McLuhan [12]. The following verbal expressions used in some of the memes we examined do show this phenomenon.

a. 'Utekmu ning endi' (Where is your brain?). In Javanese, 'utek' is the lowest grade of politeness and the rudest. Instead, people may use another form which is more acceptable socially like 'pikiranmu' (your common sense).

b. 'Woiii!!!...anjincc!!!' (Wow...dog!). Here, the user tries to manipulate the form using 'pun' into 'anjicc' instead of 'anjing'.

c. 'Waktu pertama kulihat dirimu HADIR' (The first time I saw your presence). This is another manipulation of form, initially it was HADIR then changed into KAFIR, meaning atheist.

d. 'Bantu aku melilitkan kawat ini ke mulutnya' (Please help me to wrap her mouth with this rope). In normal condition, this expression sounds very rude and unacceptable socially.

e. 'Serpihan attitude untukmu' (Flakes of attitude for you). This expression employs code switching from Indonesian language into English. It sounds rather unusual however, to hear flakes of attitude which suggests a unique perception of the meme maker.

\subsection{Perceptions of Respondents}

The 25 respondents generally agree that they enjoy sending their messages using memes on twitter because they believe that meme has the quality of being 'fluid' and expressive. Besides, memes are visually constructed using the characters either in cartoon films or other conventional media which are familiar to their target audience like Cinderella, IpinUpin, Barbie, Avenger, Thanos, etc.

With regard to the utility of conveying messages through memes, 8 of them (32\%) say that they utilize memes to convey humour. The expressive and representative utilities of meme were made by 10 respondents $(40 \%)$. Only 1 respondent (4\%) confessed that they do it to satirize and the rest belongs to others. In terms of motivation to use memes, they mentioned of using them to express sarcasm, to mock, to protest, to curse, and to give advice. In identifying the most memorable memes, the respondents claim that cartoons, figures, animals, and social circumstances were their favourite.

The only contrast between result of the content analysis and the receptive study lays on one function of meme as a means of giving advice. However, this notion is verbalized in a rather less acceptable manner like the dictions in Javanese 'utekmu' (your brain), 'bangsat' (bastard), 'ajg' that stands for 'anjing' (dog) which are very rude. With regard to politeness, there seems to be different standard of politeness employed by the millennials. Mainly because they take it as purely self-representation as asserted by Burk and Kraut [6] in which the continuum of measurement is no longer face to face interaction with a commitment to protect other's face and dignity.

\section{CONCLUSION}

After looking very closely at all of the data and infer respondents' response in terms of advantages, use, and the favourite memes that they provide in the google survey we come to the conclusion that there has been a serious shift of quality and standard in terms of politeness employed by the millennials in their memes. Visually, preference of materials used for passing on information were drawn mainly from cartoon films, images, and signs familiar to most of the audience. For that reason, a good understanding of intertextual meaning drawn from different resources is a must and they should be updated with any news and incidence taking place in the world. This is in line with the nature of twitter for being short (140 characters), used for mutual connectivity and to build relationship in order to enlarge links and collaboration. One thing which is specific of twitter is its function as a social media to tell what is going on in the world.

\section{ACKNOWLEDGMENT}

The research team would like to extend our gratitude to our English Department students, especially Nour Anggrahini and Hafida Anggi Pratikasari for their participation in the data collecting and analysis processes. Acknowledgements and appreciation to University Centre of Excellence Javanologi for Javanese Traditions Universitas Sebelas Maret for funding the publication.

\section{REFERENCES}

[1] Anderson, B. (2006). Imagined Communities. Reflections on the Origin and Spread of Nationalism. Revised ed. London: Verso.

[2] Anık, Cengiz et al. (2017). The user Indicative Language of Social Media: Emojis. Article in AJIT-e Online Academic Journal of Information Technology. DOI: 10.5824/13091581.2017.1.003.x. Retrieved on September 30, 2020.

[3] Arafah, Burhanuddin and Hasyim, Muhammad. (2019). The Language of Emoji in Social Media. 
The Second Annual International Conference on Language and Literature, 2019. KnE Social Sciences, pages 494-504. DOI 10.18502/kss.v3i19.4880. 2019. Retrieved on September 30, 2020.

[4] Brown, P., \& Levinson, S. C. (1987). Politeness: Some universals in language usage. New York: Cambridge University Press.

[5] Burgett, Bruce and Hendler, Glenn. (2014). Keywords for American Cultural Studies. New York: NYU Press.

[6] Burke, M., \& Kraut, R. (2008). Mind your Ps and Qs: the impact of politeness and rudeness in online communities. Paper presented at the Proceedings of the 2008 ACM conference on Computer supported cooperative work, San Diego, CA, USA.

[7] Fang, K. (2020). Turning a Communist Party Leader into an Internet Meme: The Political and Apolitical Aspects of China's Toad Worship Culture. Taylor \& Francis.

[8] Harlow, S., JT Rowlett, LK Huse. (2020). 'Kim Davis be like.... ': A Feminist Critique of Gender Humor in Online Political Memes. Taylor \& Francis Online.

[9] Huntington, HE. (2017). Affect and Effect of Internet Memes. Assessing Perceptions and Influence of Online User-Generated Political Discourse as Media. CSU Dissertation.

[10] Holtgraves, T. (2002). Language as social action: Social psychology and language use. Mahwah, NJ: Lawrence Erlbaum Associates.

[11] Kress, Gunther. (2010). Multimodality: A Social Semiotic Approach to Contemporary Communication. London: Routledge.

[12] McLuhan, Marshal. (1964). Global Village. Transformations in World Life and Media in the 21 st Century. Retrieved on Monday, October 12, 2020

[13] Metts, S., \& Grohskopf, E. (2003). Impression management: Goals, strategies, and skills. In J. O. Greene \& B. R. Burleson (Eds.), Handbook of communication and social interaction skills (pp. 357-399). Orlando, FL: Academic Press.

[14] Merriam-Webster. (n.d). Definition of meme. In Meriam-Webster.com dictionary. Retrieved on May 10, 2020

[15] Monnoyer-Smith, L., \& Wojcik, S. (2012). Technology and the quality of public deliberation: A comparison between on and offline participation. International Journal of Electronic Governance, 5(1), 24-44.

[16] Morand, D. A. (2000). Language and power: An empirical analysis of linguistic strategies used in superior-subordinate communication. Journal of Organizational Behavior, 21, 235-248.

[17] Van Olmen, Daniel. (2020). Politeness in language. Oxford Bibliographies: Linguistics. ed. I Mark Aronoff. New York: Oxford University Press, 2017. Retrieved on September 29, 2020

[18] Žižek, Slavoj. (1983). Mapping Idology. London New York: VERSO.

[19] D. Djatmika, A.H. Wibowo, Sugini, H. Halim, B. Mohamad. (2020). Multimodal Strategies in Teaching Children with Autism: A Discourse Analysis. Systematic Review Pharmacy 11 (2), 219-229 